Supporting Information for the Manuscript Entitled

\title{
Control of Structure in Multicompartment Micelles by Blending $\mu$ - ABC Star Terpolymers with AB Diblock Copolymers in Water
}

\author{
Zhibo Li, ${ }^{\dagger}$ Marc A. Hillmyer, ${ }^{, \dagger}$ and Timothy P. Lodge ${ }^{*,+,}$ \\ University of Minnesota, Minneapolis, Minnesota 55455
}

The supporting information includes complementary cryoTEM images with larger field view for micelle solution mixtures at different aging time.

*Authors for correspondence: hillmyer@chem.umn.edu, lodge@chem.umn.edu

'Department of Chemistry and ${ }^{\ddagger}$ Department of Chemical Engineering and Materials Science 

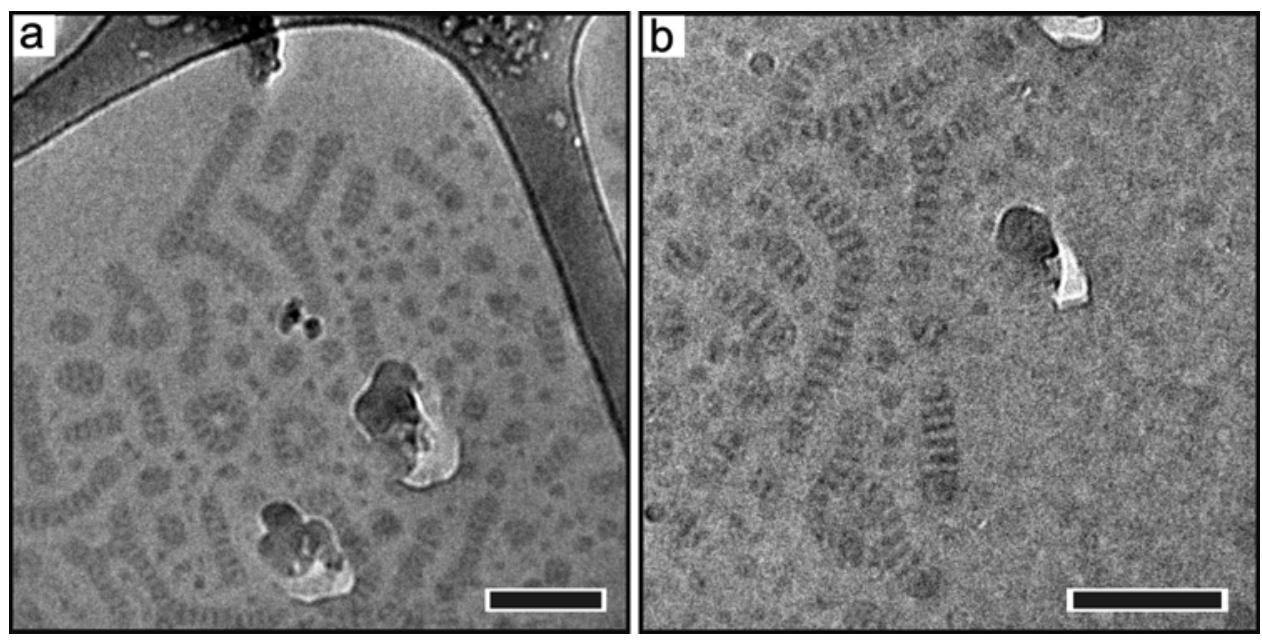

Figure S1. CryoTEM images obtained from a 1 wt $\% \mathrm{H}_{2} \mathrm{O}$ solution of $\mu$-EOF(2-6-2). Scale bar indicates $100 \mathrm{~nm}$. 


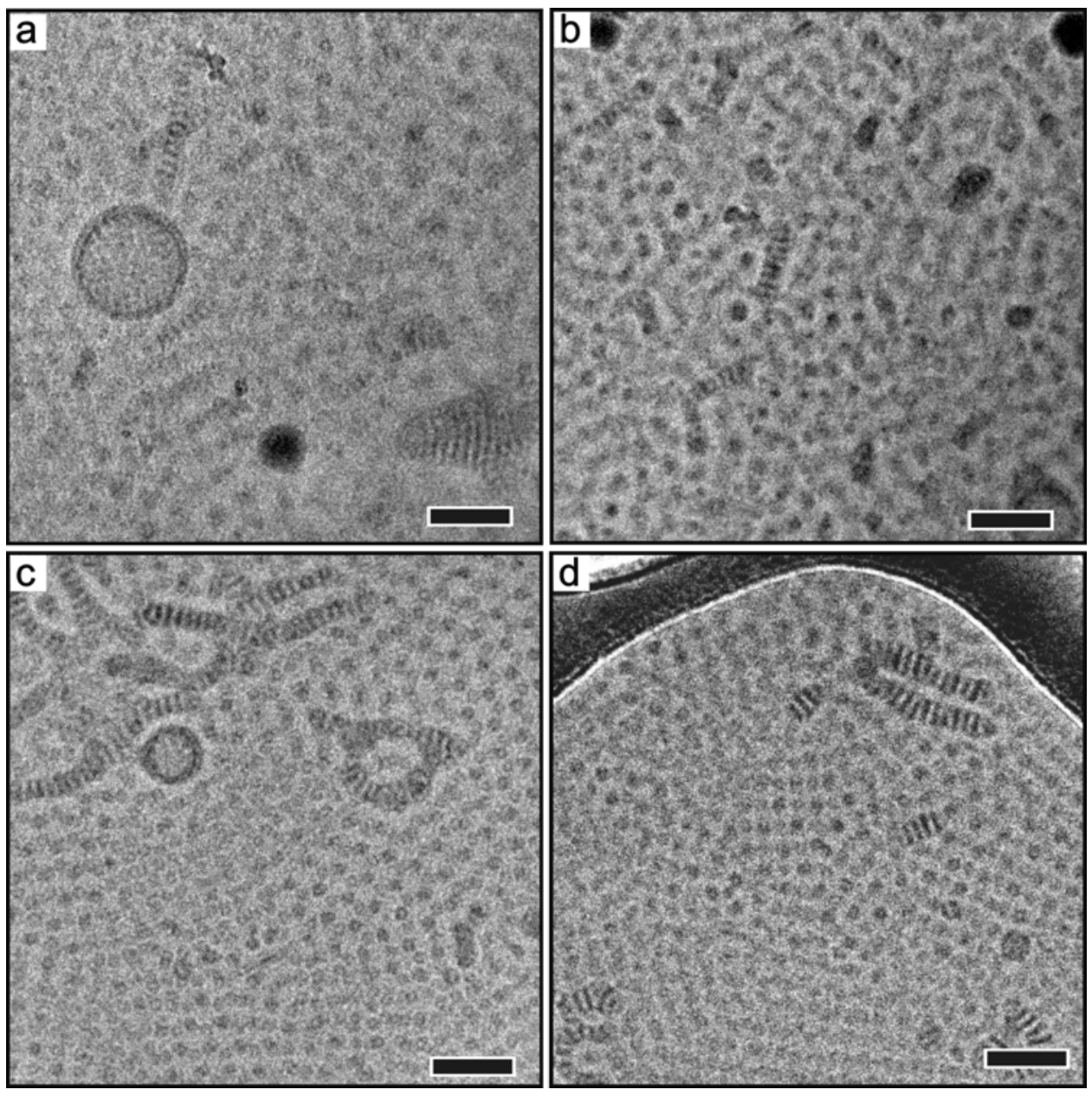

Figure S2. CryoTEM images obtained from a 1 wt $\% \mathrm{H}_{2} \mathrm{O}$ solution of the post-mixture of $\mu$ EOF(2-6-2)/EO(2-6) at week-1. Scale bar indicates $100 \mathrm{~nm}$. 


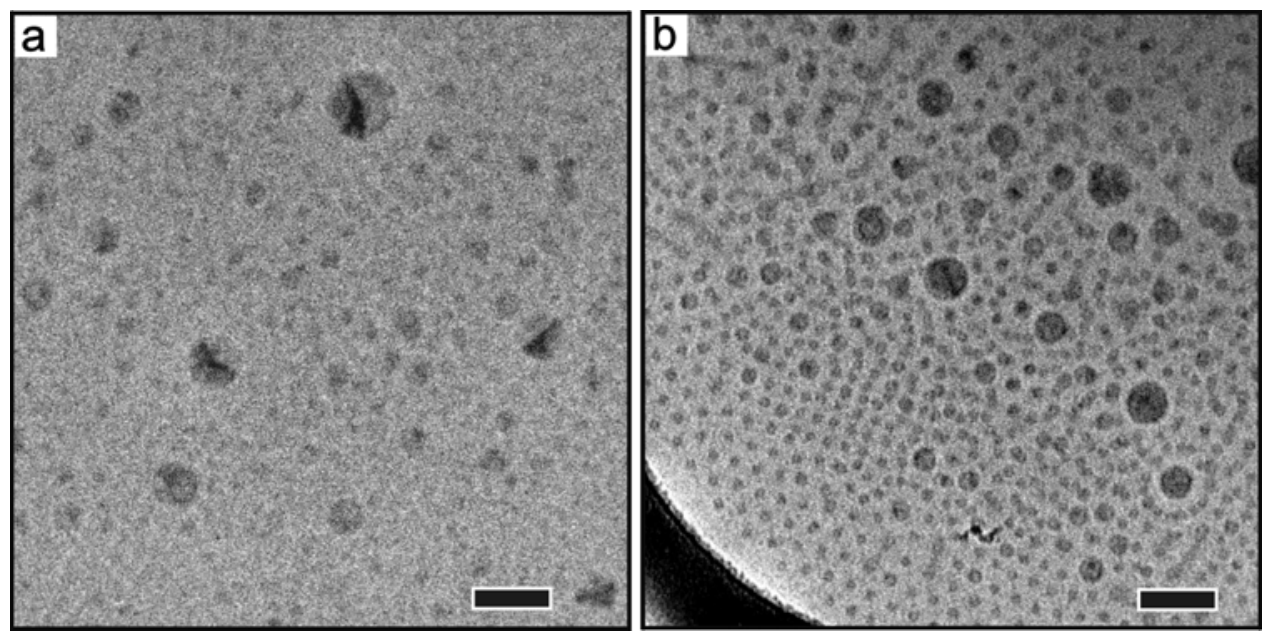

Figure S3. CryoTEM images obtained from a 1 wt $\% \mathrm{H}_{2} \mathrm{O}$ solution of the post-mixture of $\mu$ EOF(2-6-2)/EO(2-6) at week-9. Scale bar indicates $100 \mathrm{~nm}$. 


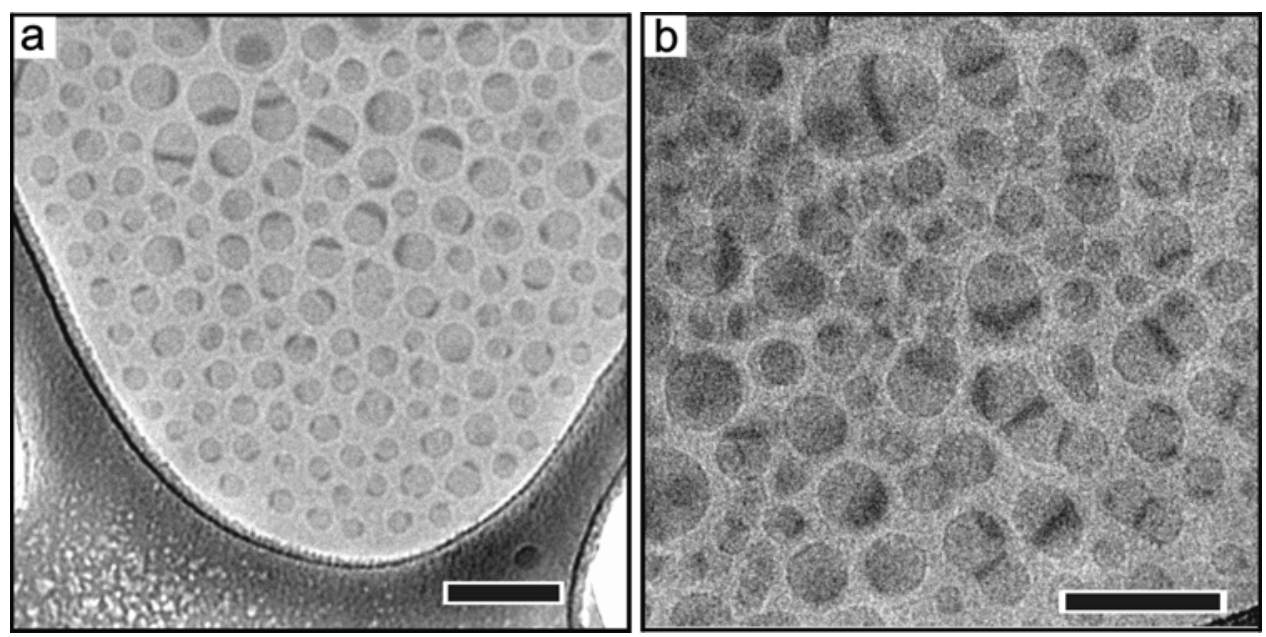

Figure S4. CryoTEM images obtained from a 1 wt $\% \mathrm{H}_{2} \mathrm{O}$ solution of the post-mixture of $\mu$ EOF(2-6-2)/EO(2-6) at week-15. Scale bar indicates $100 \mathrm{~nm}$. 

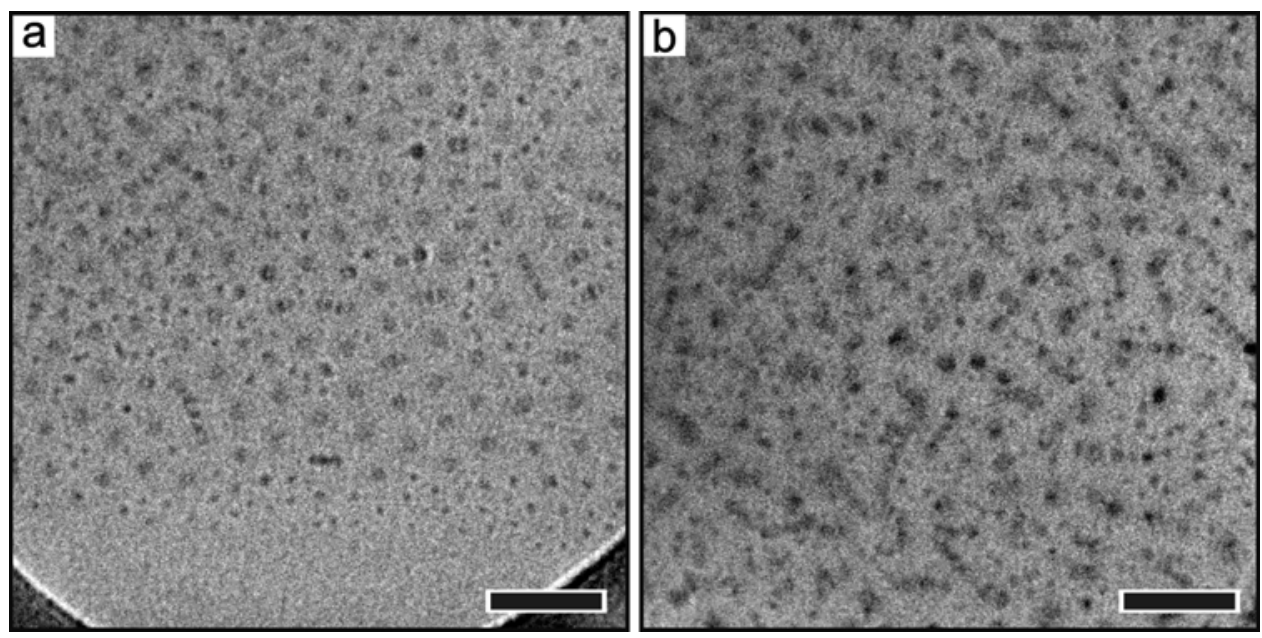

Figure S5. CryoTEM images obtained from a 1 wt $\% \mathrm{H}_{2} \mathrm{O}$ solution of the post-mixture of $\mu$ EOF/EO(2-9) at week-1. Scale bar indicates $100 \mathrm{~nm}$. 

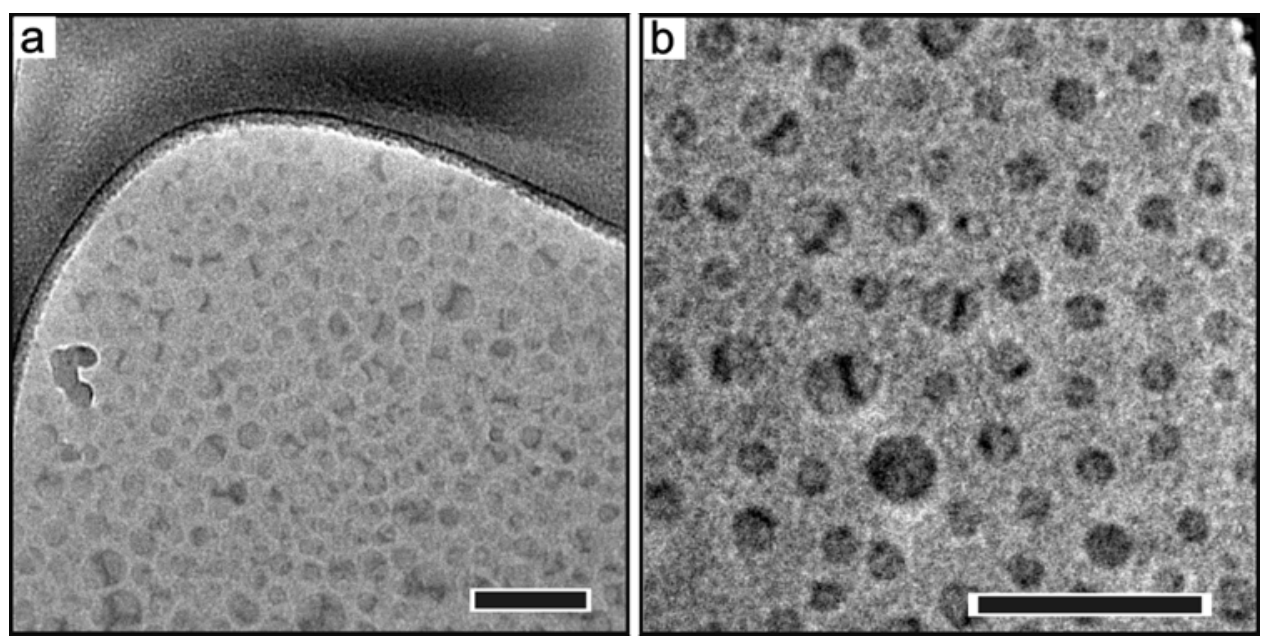

Figure S6. CryoTEM images obtained from a 1 wt\% $\mathrm{H}_{2} \mathrm{O}$ solution of the post-mixture of $\mu$ EOF(2-9-2)/EO(2-9) at week-15. Scale bar indicates $100 \mathrm{~nm}$. 

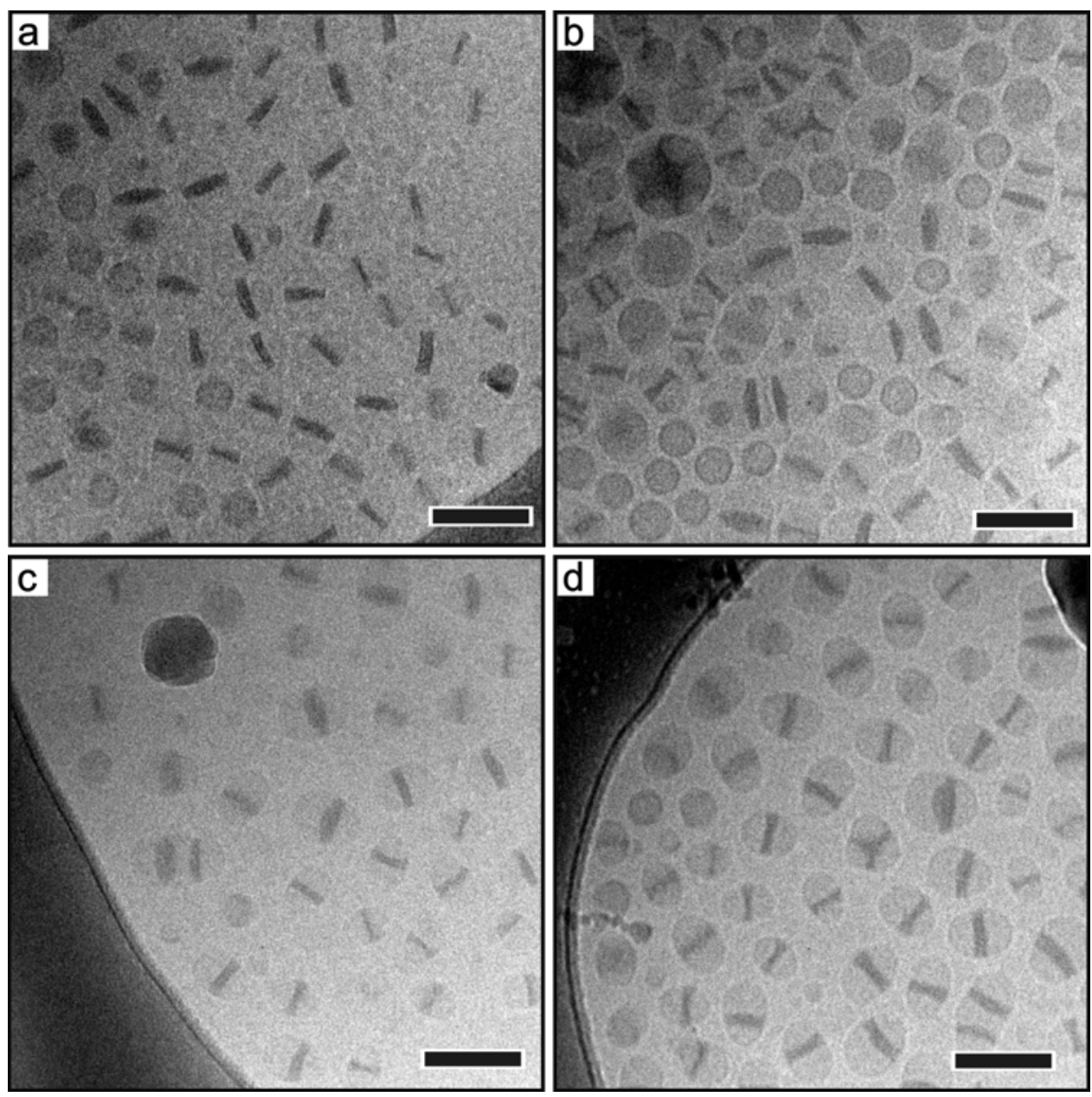

Figure S7. CryoTEM images obtained from a 1 wt $\% \mathrm{H}_{2} \mathrm{O}$ solution of the post-mixture of $\mu$ EOF(2-9-2)/EO(2-9) at week-15. Scale bar indicates $100 \mathrm{~nm}$. 

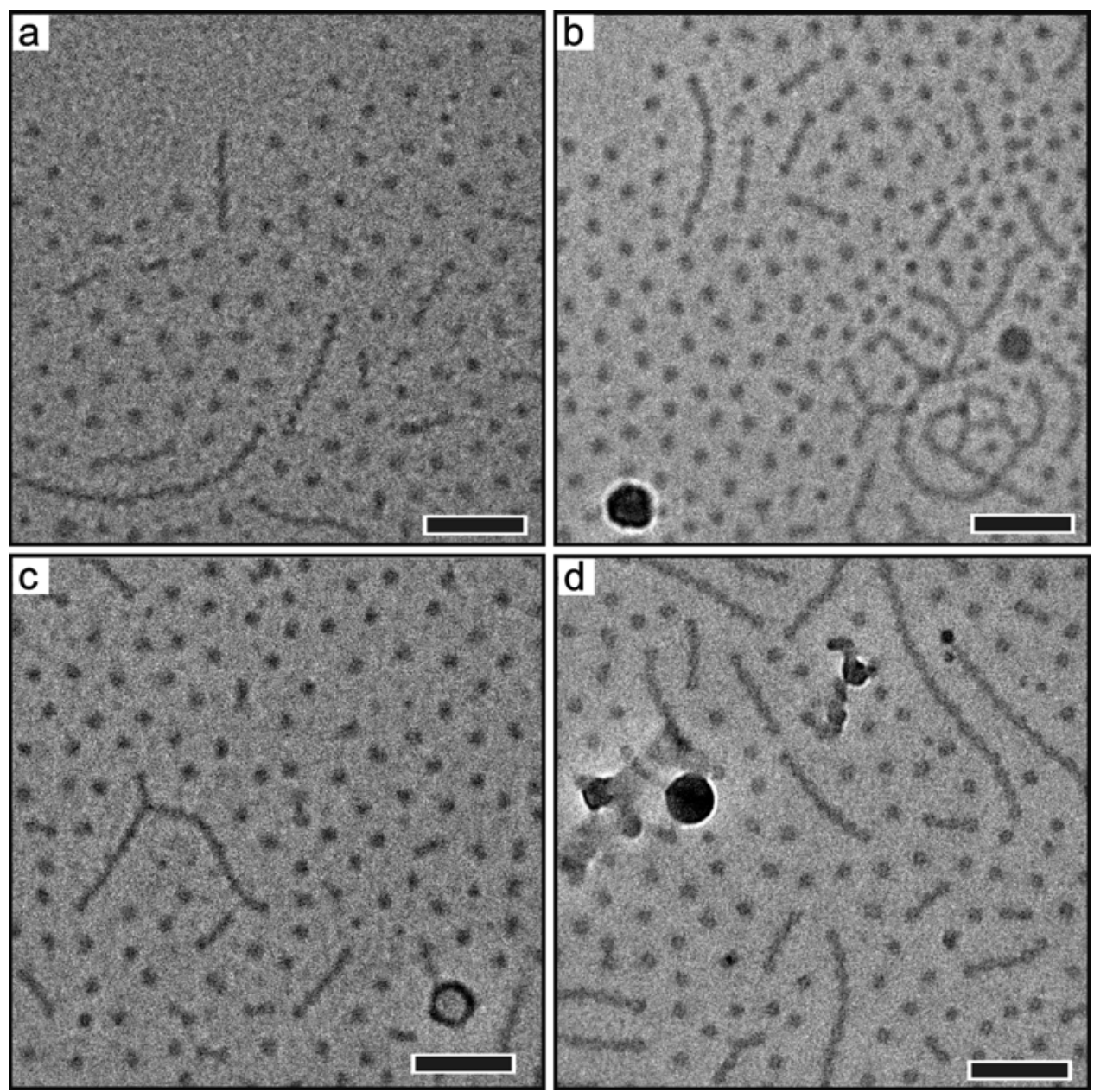

Figure S8. CryoTEM images obtained from a $1 \mathrm{wt} \% \mathrm{H}_{2} \mathrm{O}$ solution of the pre-mixture of $\mu$ EOF(2-6-2)/EO(2-6) at week-3. Scale bar indicates $100 \mathrm{~nm}$. 

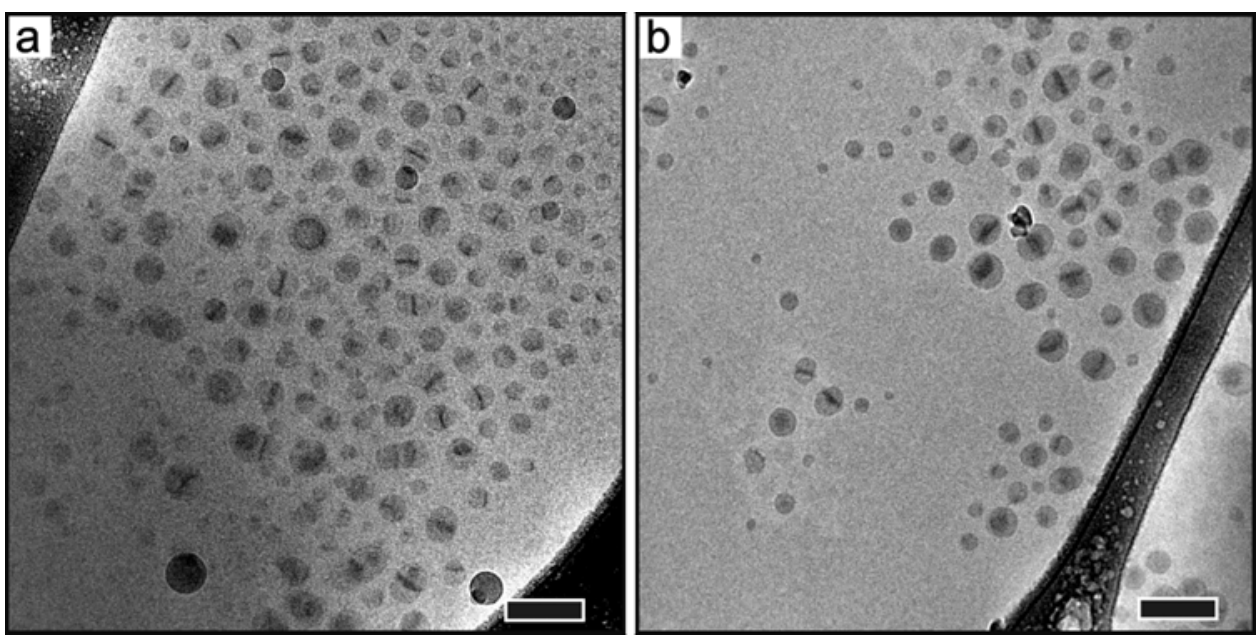

Figure S9. CryoTEM images obtained from a 1 wt\% $\mathrm{H}_{2} \mathrm{O}$ solution of the pre-mixture of $\mu$ EOF(2-6-2)/EO(2-6) at week-15. Scale bar indicates $100 \mathrm{~nm}$. 


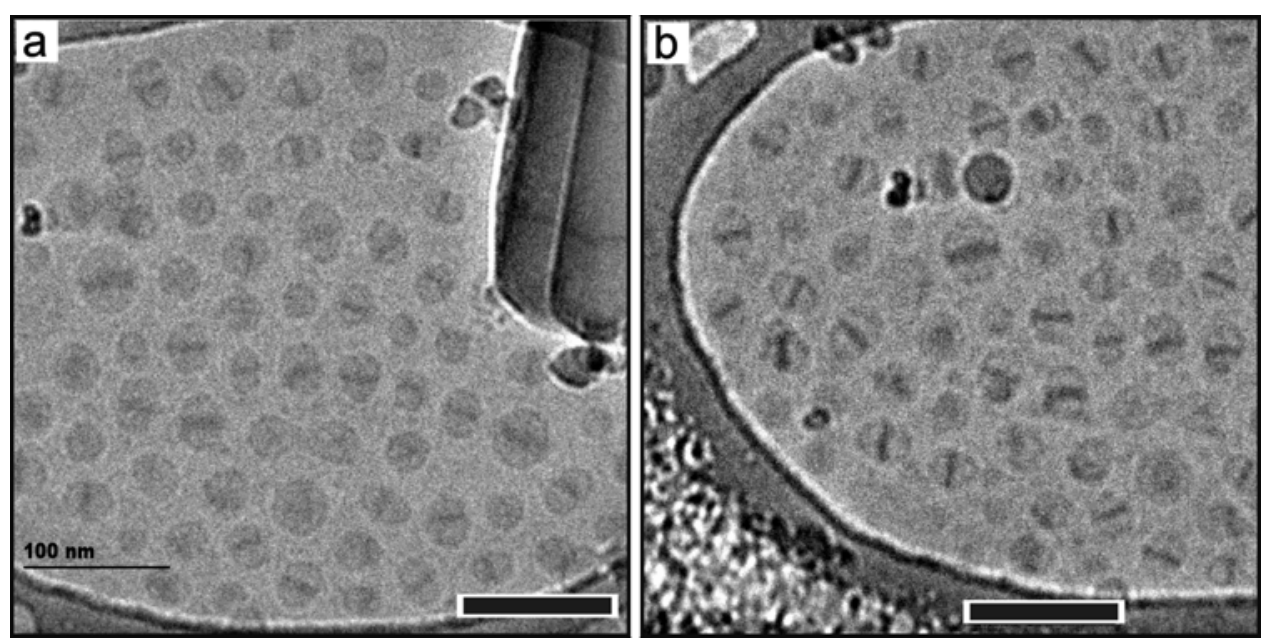

Figure S10. CryoTEM images obtained from a $1 \mathrm{wt} \% \mathrm{H}_{2} \mathrm{O}$ solution of the pre-mixture of $\mu$ $\mathrm{EOF}(2-6-2) / \mathrm{EO}(2-6)$ at week-25. Scale bar indicates $100 \mathrm{~nm}$. 